\title{
Inhibition of eukaryotic initiation factor 3B suppresses proliferation and promotes apoptosis of chronic myeloid leukemia cells
}

\author{
Laiquan Huang ${ }^{1, B, D}$, Kun He ${ }^{1, B}$, Jianxin Wang 1, , Jiawei Yan ${ }^{1, C}$, Yizhi Jiang ${ }^{1, C}$, \\ Zhongling Wei ${ }^{1, E}$, Jun Zhang ${ }^{1, E}$, Guangxi Li ${ }^{1, E}$, Lili Sheng ${ }^{2, A, F}$ \\ ${ }^{1}$ Department of Hematology, Yijishan Hospital, First Affiliated Hospital of Wannan Medical College, Wuhu, China \\ ${ }^{2}$ Department of Oncology, Yijishan Hospital, First Affiliated Hospital of Wannan Medical College, Wuhu, China \\ A - research concept and design; $\mathrm{B}$ - collection and/or assembly of data; $\mathrm{C}$ - data analysis and interpretation; \\ $\mathrm{D}$ - writing the article; $\mathrm{E}$ - critical revision of the article; $\mathrm{F}$ - final approval of the article
}

Address for correspondence

Lili Sheng

E-mail: 13605535185@163.com

\section{Funding sources}

Natural Science Research Project of Colleges and Universities in Anhui Province, China; grant No. KJ2017A263.

Conflict of interest

None declared

Received on December 1, 2018

Reviewed on December 23, 2018

Accepted on June 27, 2019

Published online on November 28, 2019

Cite as

Huang L, He K, Wang J, et al. Inhibition of eukaryotic

initiation factor $3 \mathrm{~B}$ suppresses proliferation and promotes

apoptosis of chronic myeloid leukemia cells. Adv Clin Exp Med.

2019:28(12):1639-1645. doi:10.17219/acem/110323

DOI

10.17219/acem/110323

Copyright

Copyright by Author(s)

This is an article distributed under the terms of the

Creative Commons Attribution Non-Commercial License

(http://creativecommons.org/licenses/by-nc-nd/4.0/)

\begin{abstract}
Background. Eukaryotic translation initiation factor 3B (elF3b) has been reported to be overexpressed in colon, bladder and prostate cancers as well as in glioblastoma. However, there is no report on any correlation of elF3b gene expression with cell proliferation and apoptosis in chronic myeloid leukemia (CML).

Objectives. In this study, we evaluated the role of elF3b in cell proliferation and apoptosis in CML.

Material and methods. Samples from patients with CML and CML cell lines were used. Quantitative RT-PCR, siRNA transfection, flow cytometry, and western blot analysis were performed.

Results. Quantitative RT-PCR revealed that the expression of elF3b mRNA in CML patients was higher than that in the non-malignant controls. The proliferation of CML cells decreased after transfection of the cells with siRNA. The proportion of cells in the $\mathrm{G} 1$ and $\mathrm{S}$ phases in the experimental group decreased after transfection, while the number of cells in the G2/M phase increased, as compared with the control group. The total cell apoptosis percentage in the shelF3b group (transduction with lentivirus-anti-elF3b in K562 cells) was higher than the shCtrl group (transduction with empty-vector lentivirus in K562 cells) after transfection. Caspase $3 / 7$ activity was higher and the expression of anti-apoptotic protein BCL-2 was lower in the shelF3b group than in the shCtrl group after transfection.
\end{abstract}

Conclusions. Our results suggest that downregulation of elF3b expression inhibits proliferation and induces apoptosis in CML cells.

Key words: cell proliferation, eukaryotic initiation factor 3b, chronic myeloid leukemia 


\section{Introduction}

Chronic myeloid leukemia (CML) is a hematopoietic stem cell (HSC) malignancy that results from the formation of the Philadelphia chromosome due to reciprocal chromosomal translocation $\mathrm{t}(9 ; 22)$ (q34.12; $\mathrm{q} 11.23)$, and it accounts for $15-20 \%$ of all leukemias. ${ }^{1}$ Patients with CML need to be treated for life; moreover, the prognosis of patients with blastic transformation of CML is extremely poor. Thus, there is an unmet need to find better treatments for CML.

Eukaryotic initiation factors (eIFs) are a large family of proteins that regulate the rate-limiting step of protein synthesis in the initiation stage. ${ }^{2}$ To date, numerous eIFs have been identified and several of them consist of multiple subunits that determine their functions. ${ }^{3,4}$ A growing number of studies illustrate that various eIFs are aberrantly expressed or activated in different types of human cancers. ${ }^{5,6}$

There is a growing interest in understanding the mechanisms of eIFs in modulating gene translation initiation and how they promote oncogenesis. Scientists have hypothesized that an increased rate of translation would affect the downstream mRNA synthesis and that a high level of eIFs could enhance the translation of these mRNAs. Preclinical studies have shown that overexpression of eIFs resulted in cells transforming into those with cancerous characteristics, as demonstrated by pervasive growth and increased proliferation. ${ }^{7}$

The largest group of these eIFs, eukaryotic translation initiation factor 3 (eIF3), consists of 13 subunits (eIF3a through eIF3m) with a total molecular mass of $700 \mathrm{kDa}$, and plays an essential role in the initiation of translation. ${ }^{8}$ eIF3 mediates several steps of the translation initiation pathway, which includes recruiting the eIF2-GTP-MET-tRNA (iMet) ternary complex and other eIFs to the $40 \mathrm{~S}$ ribosomal subunit to form the $43 \mathrm{~S}$ preinitiation complex, mRNA recruitment and subsequent scanning of the 5' untranslated region (UTR) and starting codon. ${ }^{9}$ eIF3b has been verified to be overexpressed in colon, bladder and prostate cancers as well as in glioblastoma due to its impact on the cellular activity of cancer cells. ${ }^{10-12}$

While several eIF proteins have been implicated in $\mathrm{CML},{ }^{6,7}$ there is no study in the literature exploring the correlation of $e I F 3 b$ expression with cell proliferation and apoptosis in CML. Therefore, that is precisely the aim of the current study.

\section{Material and methods}

\section{Sample collection and elF3b mRNA expression}

A total of 16 CML patients were enrolled in this study at the Department of Hematology of Yijishan Hospital, First Affiliated Hospital of Wannan Medical College, Wuhu, China, from January 2015 to March 2017. As controls,
16 age- and gender-matched non-malignant patients who had undergone bone marrow biopsy (12 thrombocytopenic purpura, 3 infectious diseases and 1 healthy donor) were enrolled. During the bone marrow biopsy, $2 \mathrm{~mL}$ of bone marrow sample was obtained from each participant; mononuclear cells were then isolated. This was followed by total RNA extraction and eIF3b mRNA was detected with quantitative real-time reverse transcription polymerase chain reaction (qRT-PCR). This study was approved by the Ethics Committee of Yijishan Hospital, First Affiliated Hospital of Wannan Medical College Hospital. The participants provided written informed consent.

\section{elF3b expression in different leukemia cell lines}

TK-6, K562 and Jurkat cell lines were purchased from the Shanghai Institutes for Biological Science (Shanghai, China). After resuscitation, these cells were maintained in RPMI-1640 medium (Gibco, Carlsbad, USA) containing $10 \%$ fetal bovine serum (Gibco) and $1 \%$ penicillin/streptomycin (Corning, Lowell, USA) at $37^{\circ} \mathrm{C}$ with a humidified atmosphere of $5 \% \mathrm{CO}_{2}$. Meanwhile, mononuclear cells were isolated from the bone marrow of 3 control subjects (patients without malignancies) and were defined as the control group. The expression of eIF3b mRNA was detected with qRT-PCR.

\section{Detection of K562 cell transduction, proliferation and apoptosis}

K562 cells were transduced with the lentivirus-anti-eIF3b vector (LVpGCSIL-004PSC2749-1; Shanghai Gemma, Shanghai, China) and identified as the sheIF3b group (the sequences of anti-eIF3b: 5'-GCUACAAGCUUGACAAGCAdTdT-3' (F) and 5'- UGCUUGUCAAGCUUGUAGCdTdT-3' (R)); those transduced with an empty vector (psc3741, Shanghai Gemma) served as the control group (shCtrl group, irrelevant sequence). The level of fluorescence was observed under a fluorescence microscope; all transduction rates were more than 90\%. Briefly, qRT-PCR, western blotting, CCK-8 and fluorescence-activated cell sorting (FACS) were used to examine the eIF3b mRNA level, protein level, cell proliferation, cell cycles, and apoptosis in the K562 cells. For western blot analysis, the total protein was adjusted into equal amounts and subjected to sodium dodecyl sulfate polyacrylamide gel electrophoresis (SDS-PAGE). Specific antibodies were used to detect each corresponding protein. The antibodies used for western blotting analysis are listed in Table 1.

\section{RNA extraction and $\mathrm{qRT}-\mathrm{PCR}$ analysis}

Total RNA samples from cells were extracted with TRIzol reagent (Invitrogen, Carlsbad, USA) according to the manufacturer's instructions. The extracted RNA 
Table 1. Details of the antibodies used

\begin{tabular}{|l|c|c|c|}
\multicolumn{1}{|c|}{ Antibody name } & Company & Country & Dilution ratio \\
\hline $\begin{array}{c}\text { Primary antibody } \\
\text { Mouse Anti-Flag }\end{array}$ & Sigma & USA & $1: 2000$ \\
\hline Mouse anti-GAPDH & Santa-Cruz & USA & $1: 2000$ \\
\hline Anti-BCL2 & Abcam & USA & $1: 2000$ \\
\hline Anti-GAPDH & Santa-Cruz & USA & $1: 2000$ \\
\hline $\begin{array}{c}\text { Secondary antibody } \\
\text { Goat Anti-Mouse IgG } \\
\text { Anti-Mouse lgG }\end{array}$ & Santa-Cruz & USA & $1: 2000$ \\
\hline
\end{tabular}

was pretreated with RNase-free DNase, and $1 \mu \mathrm{g}$ of RNA from each sample was used for cDNA synthesis with random hexamers (RNA to cDNA EcoDry ${ }^{\text {TM }}$ Premix; TAKARA, Kusatsu, Japan). The cDNA products were subjected to qRT-PCR with a SYBR FAST Mastermix kit (KAPA, Boston, USA). The following primer sequences were used: - eIF3b forward primer:

5'CGGTGCCTTAGCGTTTGTG-3';

- eIF3b reverse primer:

5'-CGGTCCTTGTTGTTCTTCTGC-3';

- GAPDH forward primer:

5'-TGACTTCAACAGCGACACCCA-3';

- GAPDH reverse primer:

5'-CACCCTGTTGCTGTAGCCAAA-3'.

The PCR amplification was performed as follows: $95^{\circ} \mathrm{C}$ for $5 \mathrm{~min}$, followed by 40 cycles of $95^{\circ} \mathrm{C}$ for $4 \mathrm{~s}$ and $61^{\circ} \mathrm{C}$ for $30 \mathrm{~s}$. The PCR amplification was performed in triplicate. The qRT-PCR results were calculated with the $2^{-\Delta \Delta} \mathrm{Ct}$ method.

\section{Western blot analysis}

Western blotting was performed for the detection of eI$\mathrm{F} 3 \mathrm{~b}$ and $\mathrm{Bcl}-2$ expression. The total protein was extracted from cells lysed in RIPA buffer (Thermo Fisher Scientific, Waltham, USA) containing phosphatase and protease inhibitors. Then, $20 \mu \mathrm{g}$ of protein samples were subjected to SDS-PAGE and transferred onto polyvinylidene fluoride membranes (Merck Millipore, Bedford, USA). After blocking with $5 \%$ skim milk for $2 \mathrm{~h}$, the membranes were incubated with the corresponding primary antibodies overnight at $4^{\circ} \mathrm{C}$. Then, the membranes were incubated with the appropriate HRP-conjugated secondary antibodies for $1 \mathrm{~h}$ at room temperature. The bands were visualized using an enhanced chemiluminescence (ECL) kit (Merck Millipore), followed by exposure to X-ray film. All of the antibodies used are listed in Table 1.

\section{CCK-8 assay}

After transduction, cells coupled with CCK-8 dye were incubated with $5 \% \mathrm{CO}_{2}$ at $37^{\circ} \mathrm{C}$. The proliferation was evaluated at timepoints of $4 \mathrm{~h}, 24 \mathrm{~h}, 48 \mathrm{~h}, 72 \mathrm{~h}$, and $96 \mathrm{~h}$. The plates were tested and the fluorescence value was read once a day with a microplate reader (Biotek, Winooski, USA). The fluorescence values of each of the 5 days were collected and analyzed to create a proliferation curve.

\section{FACS analysis of cell cycle and apoptosis}

For the analysis of the cell cycle, cells were collected $48 \mathrm{~h}$ after transduction. The cells were washed 3 times with phosphate-buffered saline (PBS) and fixed in $70 \%$ prechilled ethanol at $4^{\circ} \mathrm{C}$ for $1 \mathrm{~h}$. The cells were then suspended in $500 \mu \mathrm{L}$ of PBS combined with $50 \mu \mathrm{g} / \mathrm{mL}$ of propidium iodide (PI) and $100 \mu \mathrm{g} / \mathrm{mL}$ of ribonuclease, and incubated at $4^{\circ} \mathrm{C}$ for $30 \mathrm{~min}$ in the dark. A 300-mesh nylon net was used to filter and separate the aggregated cells. The cell cycle was analyzed with flow cytometry on a FACScan (BD Biosciences, East Rutheford, USA).

For the analysis of apoptosis, $48 \mathrm{~h}$ after transduction, the cells were collected and washed 3 times with PBS, then suspended in $100 \mu \mathrm{L}$ of PBS; $1 \mu \mathrm{L}$ of PI was added to the cell suspension, which was incubated at $4{ }^{\circ} \mathrm{C}$ for 5 min in the dark. The cells stained with PI were detected using flow cytometry on a FACScan. The analysis was performed with a BD FACSCanto II flow cytometer and BD FACSDiva software v. 6.1.3 (BD Biosciences).

\section{Caspase-3/7 activity analysis}

Three days after transduction, cells were harvested for caspase-3/7 activity analysis using an Amplite ${ }^{\mathrm{TM}}$ Colorimetric Caspase 3/7 Assay Kit (AAT Bioquest, Sunnyvale, USA). Caspase- $3 / 7$ activity was measured using $30 \mu \mathrm{g}$ of lysate by detecting the chromophore $\mathrm{p}$-nitroaniline, which was cleaved from the labeled substrate N-acetyl-Asp-GluVal-Asp p-nitroanilide.

\section{Statistical methods}

The statistical analysis was performed using SPSS software v. 22.0 (IBM Corp., Armonk, USA). Data was presented as mean \pm standard deviation (SD). Comparisons between 2 groups were carried out with a t-test. A p-value $<0.05$ was considered statistically significant.

\section{Results}

\section{Overexpression of elF3b mRNA in CML}

The results of qRT-PCR showed that the expression of eIF3b mRNA in the CML patients was higher than that of the control group ( $<<0.01$ ) (Fig. 1A). In addition, $e I F 3 b$ was found to be overexpressed in the TK-6 ( $<<0.001)$, K562 ( $\mathrm{p}<0.001)$ and Jurkat $(\mathrm{p}<0.05)$ CML cells when compared with normal control cells (mononuclear cells isolated from the bone marrow of healthy individuals, Fig. 1B). 
A

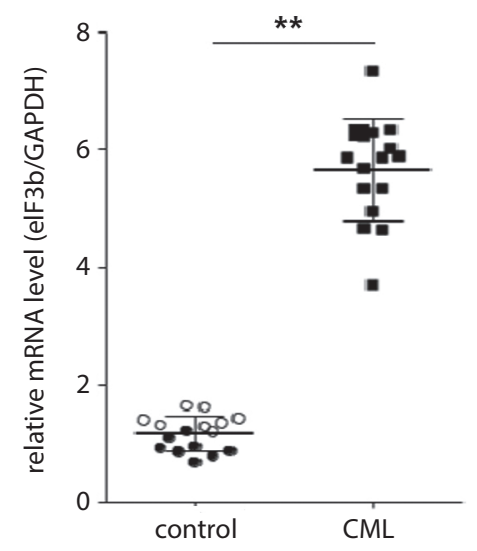

A

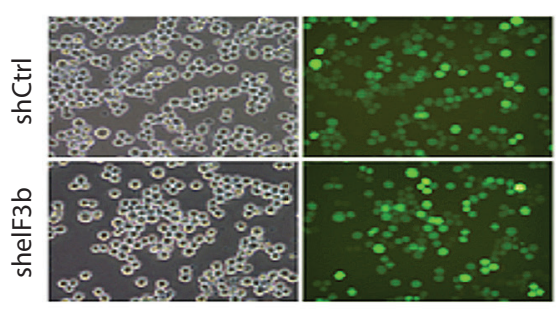

B

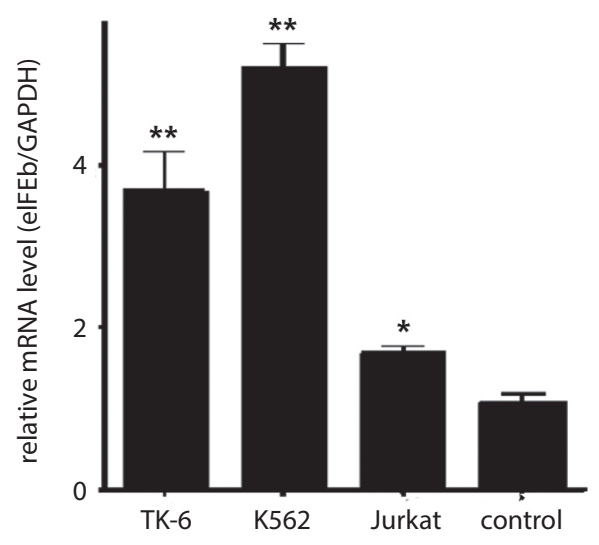

B

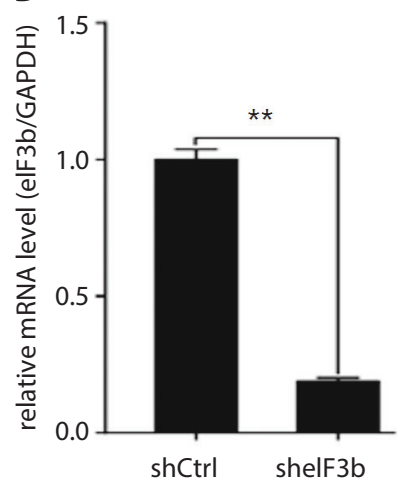

Fig. 1. Expression of elF3b mRNA in CML cells, normal control cells (mononuclear cells of bone marrow) and different cell lines; $A$ - expression of elF3b mRNA in $C M L$ and controls; $B$ - expression of elF3b mRNA in TK-6, K562 and Jurkat CML cells, and control cells

${ }^{*} p<0.05 ;{ }^{* *} p<0.01$.

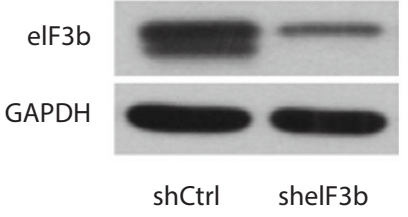

Fig. 2. Transduction of shRNA and the expression of elF3b mRNA and protein; A - transduction efficiency of shRNA in K562 cells under fluorescence microscope; B - qRT-PCR of the relative mRNA level in the shCtrl and shelF3b groups; $\mathrm{C}$ - western blotting of the level of elF3b protein in the shCtrl and shelF3b groups

${ }^{* *} \mathrm{p}<0.01$.

\section{shRNA inhibits elF3b mRNA and protein expression}

After transduction with lentivirus-anti-eIF3b or emptyvector lentivirus in the K562 cells for 3 days, the fluorescence expression was observed under a fluorescence microscope, which showed that the transduction efficiency of both was over $90 \%$ (Fig. 2A). After 3 days, the expression of eIF3b mRNA and protein had both decreased markedly in the sheIF3b group compared with the shCtrl group (Fig. 2B,C).

\section{Downregulation of elF3b mRNA-inhibited proliferation of $\mathrm{K} 562$ cells}

The CCK- 8 assay showed no significant difference in baseline optical density (OD) between the sheIF3b and shCtrl groups. On days 3, 4 and 5 after transduction, the OD value of the sheIF3b group was lower than that of the shCtrl group (Fig. 3A,B), a finding which suggests that the inhibition of eIF3b mRNA suppresses the proliferation of K562 cells.
A

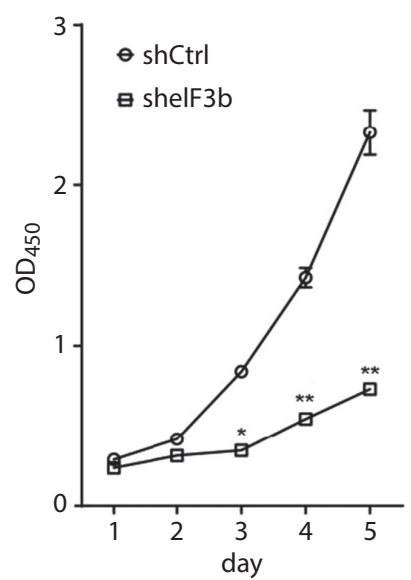

B

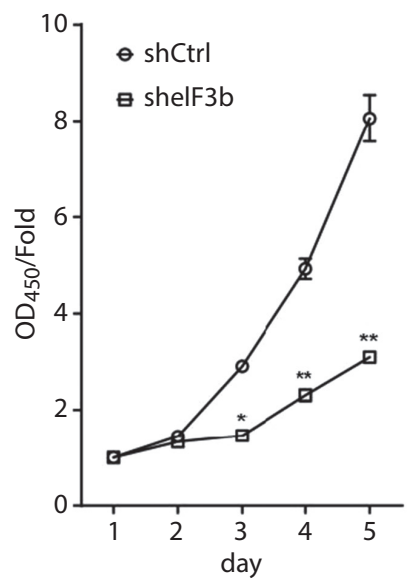

Fig. 3. Effect of elF3b mRNA downregulation on the proliferation of K562 cells; $\mathrm{A}-\mathrm{OD}_{450}$ value in the shCtrl and shelF3b groups 5 days after transduction; $\mathrm{B}-\mathrm{OD}_{450}$ value in the shCtrl and shelF3b groups 5 days after transduction

${ }^{*} p<0.05$; ${ }^{* *} p<0.01$. 


\section{Effect of elF3b gene downregulation on $\mathrm{K} 562$ cell cycles}

Following transduction with shRNA lentivirus - on day 5 - the proportion of cells in the G1 $(\mathrm{p}<0.01)$ and $\mathrm{S}$ phases $(\mathrm{p}<0.05)$ of the sheIF3b group was lower than that of the shCtrl group, while the proportion of cells in the $G 2 / M$ phase $(p<0.01)$ was higher than in the $s h C$ trl group (Fig. 4A,B).

\section{Effect of elF3b mRNA downregulation on the apoptosis of $\mathrm{K} 562$ cells}

On day 5 after transduction, the total cell apoptosis percentage in the sheIF3b group was substantially higher than that of the shCtrl group ( $\mathrm{p}<0.01$, Fig. 5A,B). Caspase $3 / 7$ activity in the sheIF3b group was remarkably higher $(\mathrm{p}<0.01$, Fig. $6 \mathrm{~A})$ than that of the control group, and the expression of anti-apoptotic protein $\mathrm{Bcl}-2$ was markedly lower in the sheIF3b group than in the shCrtl group ( $\mathrm{p}<0.01$, Fig. $6 \mathrm{~B}$ ), suggesting that eIF3b downregulation promoted the apoptosis of K562 cells.

\section{Discussion}

Chronic myeloid leukemia is a clonal HSC disorder resulting from a reciprocal translocation between the long arms of ch9 and ch22, $\mathrm{t}(9 ; 22)$, which leads to the fusion of the $A B L 1$ proto-oncogene from ch9 with the $B C R$
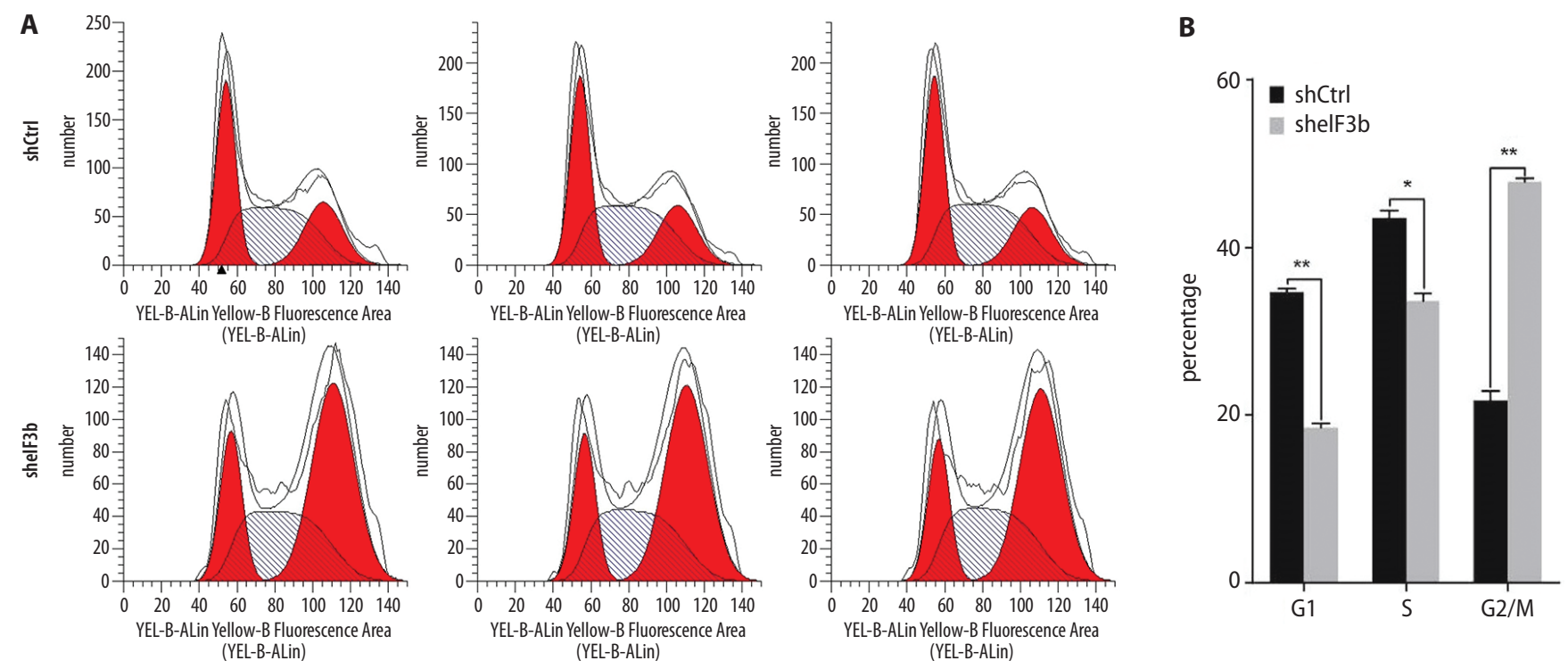

Fig. 4. Effect of elF3b gene downregulation on the cell cycles of K562 cells; A - proportion of K562 cells in different phases in the shCtrl and shelF3b groups; B - proportion of K562 cells in G1, S, and G2/M phases in the shCtrl and shelF3b groups

${ }^{*} p<0.01 ;{ }^{* *} p<0.01$.
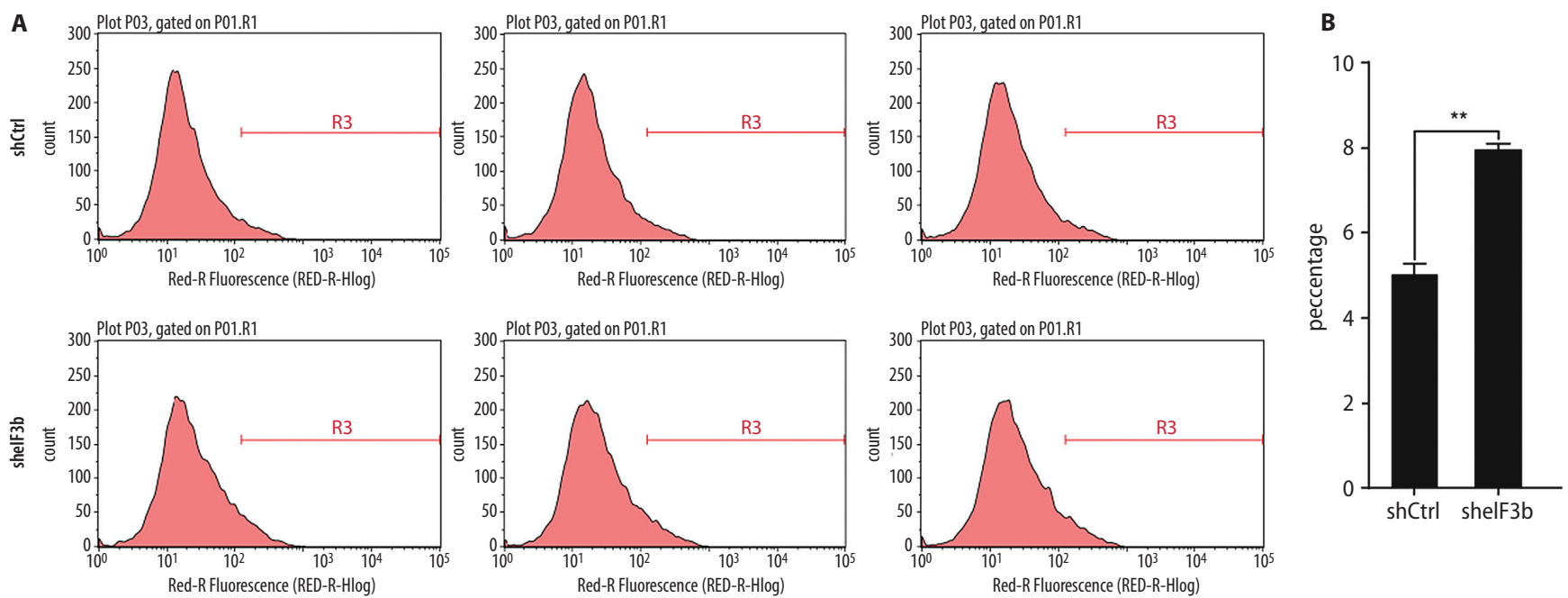

Fig. 5. Effect of elF3b gene downregulation on the apoptosis of K562 cells; A - cell apoptosis of K562 cells in the shCtrl and shelF3b groups; B - percentage of cell apoptosis in the shCtrl and shelF3b groups 
A

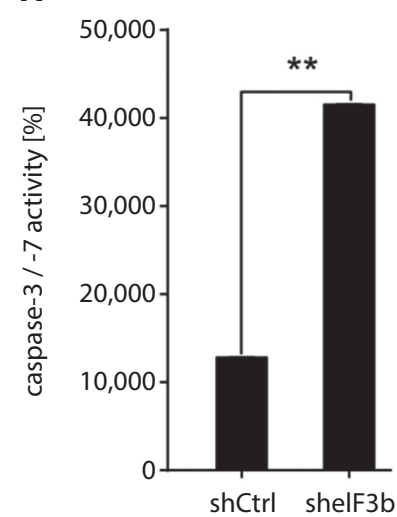

Fig. 6. Effect of elF3b gene downregulation on apoptosis-related proteins; A - caspase $3 / 7$ activity in the shCtrl and shelF3b groups; B - expression of anti-apoptotic protein BCL-2 in the shCtrl and shelF3b groups

${ }^{* *} \mathrm{p}<0.01$.

housekeeping gene on ch22 to produce the $B C R-A B L$ gene. ${ }^{13}$ This fusion gene is transcribed into BCR-ABL1 mRNA and translated into the BCR-ABL protein, which initiates the progression of CML. ${ }^{14,15}$

Dysregulation of mRNA translation leads to the aberrant activation of cellular pathways that promote cell proliferation, invasion and progression of leukemia. The main function of eIFs is in the interaction between the ribosome and mRNA, which takes part in the initial process of protein synthesis, affecting cell cycle, growth and apoptosis. ${ }^{16,17}$

$e I F 3 b$, a member of the eIF3 complex, is reported to be overexpressed in various tumor cells and acts as an oncogene. A study indicated that eIF3b mRNA is abundantly expressed in colon cancer cells, and that the downregulation of $e I F 3 b$ inhibits cell proliferation, reduces the number of cells in the G1 phase and increases the number of cells in the S/G2 phases, as well as promotes cell apoptosis. ${ }^{8}$ Another study investigating the role of eIF3b in esophageal squamous cell carcinoma (ESCC) also revealed that $e I F 3 b$ expression is much higher in ESCC tissues and ESCC cell lines, while a reduction in $e I F 3 b$ suppresses cell proliferation and stimulates cell apoptosis through the regulation of the $\beta$-catenin signaling pathway. ${ }^{18}$ In bladder and prostate cancer cells, eIF3b deletion decreases cell growth and represses the G1/S cell cycle transition by regulating cyclin $\mathrm{A}, \mathrm{E}, \mathrm{Rb}$, and $\mathrm{p} 27 \mathrm{Kip} 1$ protein expression - but not mRNA expression - and it reduces migration as well as interrupting the actin cytoskeleton and focal adhesions ${ }^{11}$ A recently published study showed that knockdown of eIF3b decreases cell viability and promotes apoptosis in osteosarcoma cells due to the regulation of tumor necrosis factor receptor superfamily member 21 (TNFRSF21). ${ }^{19}$ These findings indicate that $e I F 3 b$ is involved in tumor development and progression by acting as a cancer-promoting gene.

In clinical research, Wang et al. examined the expression of eIF3b mRNA in patients with bladder cancer and prostate cancer, and reported that eIF3b mRNA expression is much higher in cancer patients than in controls. Interestingly, they also discovered that eIF3b mRNA is positively correlated with tumor grade and could predict unfavorable survival. ${ }^{9}$ However, the role of eIF3b in CML remains unclear. In this study, we found that eIF3b mRNA expression was higher in CML patients and CML cell lines than in the controls. Downregulation of eIF3b expression suppressed CML cell proliferation, decreased G1/Sphase cells and induced cell apoptosis, which was in line with the oncogenic role of $e I F 3 b$ in other studies. Reduced eIF3b mRNA expression inhibits proliferation and promotes apoptosis in $\mathrm{K} 562$ cells. The possible explanations could be as follows: 1) eIF $3 b$ could activate the $\beta$-catenin signaling pathway, including the downstream target gene cyclin D1 and c-Myc, thus inducing cell proliferation and invasion, as well as inhibiting cell apoptosis and interfering with the cell cycle ${ }^{18}$ or; 2) $e I F 3 b$ is involved in protein synthesis and $e I F 3 b$ depletion can globally inhibit protein synthesis, which affects the proliferation and apoptosis of cancer cells. ${ }^{9}$

There were some limitations in this study. Firstly, the prognostic role of $e I F 3 b$ expression in CML patients was not investigated. Secondly, we discovered the role of $e I F 3 b$ in regulating CML cell proliferation and apoptosis, but the mechanism of how $e I F 3 b$ affects cancer cell progression was not explored. This will be the focus of future research.

In conclusion, the downregulation of $e I F 3 b$ inhibits proliferation and induces apoptosis in CML cells.

\section{ORCID iDs}

Laiquan Huang (1) https://orcid.org/0000-0002-7139-9755

Kun He (1) https://orcid.org/0000-0001-5843-2939

Jianxin Wang (1) https://orcid.org/0000-0001-9548-1465

Jiawei Yan (1) https://orcid.org/0000-0001-9887-503X

Yizhi Jiang (1) https://orcid.org/0000-0002-4812-2547

Zhongling Wei (1) https://orcid.org/0000-0002-2763-0964

Jun Zhang (1) https://orcid.org/0000-0002-1759-2829

Guangxi Li (i) https://orcid.org/0000-0002-4309-0611

Lili Sheng (1) https://orcid.org/0000-0002-9579-7328

\section{References}

1. Gutierrez LG, Noriega MF, Laudicina A, Quatrin M, Bengio RM, Larripa I. An unusual translocation, $t(1 ; 11)(q 21 ; q 23)$, in a case of chronic myeloid leukemia with a cryptic Philadelphia chromosome. Oncol Lett. 2017;13(5):3159-3162.

2. Hinnebusch AG, Lorsch JR. The mechanism of eukaryotic translation initiation: New insights and challenges. Cold Spring Harb Perspect Biol. 2012;4(10). doi:10.1101/cshperspect.a011544

3. Pestova TV, Kolupaeva VG. The roles of individual eukaryotic translation initiation factors in ribosomal scanning and initiation codon selection. Genes Dev. 2002;16(22):2906-2922.

4. Sonenberg N, Hinnebusch AG. Regulation of translation initiation in eukaryotes: Mechanisms and biological targets. Cell. 2009;136(4): 731-745.

5. Silvera D, Formenti SC, Schneider RJ. Translational control in cancer. Nat Rev Cancer. 2010;10(4):254-266.

6. Hagner PR, Schneider A, Gartenhaus RB. Targeting the translational machinery as a novel treatment strategy for hematologic malignancies. Blood. 2010;115(11):2127-2135. 
7. Spilka R, Ernst C, Mehta AK, Haybaeck J. Eukaryotic translation initiation factors in cancer development and progression. Cancer Lett. 2013;340(1):9-21.

8. Mayeur GL, Fraser CS, Peiretti F, Block KL, Hershey JW. Characterization of elF3k: A newly discovered subunit of mammalian translation initiation factor elF3. Eur J Biochem. 2003;270(20):4133-4139.

9. Hinnebusch AG. elF3: A versatile scaffold for translation initiation complexes. Trends Biochem Sci. 2006;31(10):553-562.

10. Wang Z, Chen J, Sun J, Cui Z, Wu H. RNA interference-mediated silencing of eukaryotic translation initiation factor 3 , subunit $B$ (elF3b) gene expression inhibits proliferation of colon cancer cells. World J Surg Oncol. 2012;10:119.

11. Wang H, Ru Y, Sanchez-Carbayo M, Wang X, Kieft JS, Theodorescu D. Translation initiation factor elF3b expression in human cancer and its role in tumor growth and lung colonization. Clin Cancer Res. 2013; 19(11):2850-2860.

12. Liang $H$, Ding $X$, Zhou $C$, et al. Knockdown of eukaryotic translation initiation factors 3B (elF3b) inhibits proliferation and promotes apoptosis in glioblastoma cells. Neurol Sci. 2012;33(5):1057-1062.
13. Apperley JF. Chronic myeloid leukaemia. Lancet. 2015;385(9976): 1447-1459.

14. Kavalerchik E, Goff D, Jamieson CH. Chronic myeloid leukemia stem cells. J Clin Oncol. 2008;26(17):2911-2915.

15. Savona M, Talpaz M. Getting to the stem of chronic myeloid leukaemia. Nat Rev Cancer. 2008;8(5):341-350.

16. Pestova TV, Kolupaeva VG, Lomakin IB, et al. Molecular mechanisms of translation initiation in eukaryotes. Proc Natl Acad Sci U S A. 2001; 98(13):7029-7036.

17. Lee AS, Kranzusch PJ, Cate JH. elF3 targets cell-proliferation messenger RNAs for translational activation or repression. Nature. 2015; 522(7554):111-114

18. $\mathrm{Xu} \mathrm{F}, \mathrm{Xu} C \mathrm{C}, \mathrm{Gu}$ J, et al. Eukaryotic translation initiation factor $3 \mathrm{~B}$ accelerates the progression of esophageal squamous cell carcinoma by activating beta-catenin signaling pathway. Oncotarget. 2016;7(28): 43401-43411.

19. Choi YJ, Lee YS, Lee HW, Shim DM, Seo SW. Silencing of translation initiation factor elF3b promotes apoptosis in osteosarcoma cells. Bone Joint Res. 2017;6(3):186-193. 